\title{
A 1200 V/200 A Half-Bridge Power Module Based on Si IGBT/SiC MOSFET Hybrid Switch
}

\author{
Lei Li, Puqi Ning, Xuhui Wen, and Dong Zhang
}

\begin{abstract}
The hybrid switch (HyS), which is a parallel combination of the silicon (Si) insulated gate bipolar transistors (IGBTs) and the silicon carbide (SiC) metal-oxide semiconductor field-effect transistors (MOSFETs), can realize high switching frequency at a reasonable cost. In this paper, a compact $\mathrm{HyS}$ half-bridge power module, rated at $1200 \mathrm{~V} / 200 \mathrm{~A}$, was fabricated in house and fully tested for the first time. An electrothermal model of the HyS was set up in LTspice to determine the optimal gate sequence for the HyS. To minimize the HyS power loss, the turn-on gate signals are applied to the Si IGBTs and the SiC MOSFETs simultaneously while a prior turn-off period exists between the turn-off gate signals of the Si IGBTs and the SiC MOSFETs. By considering the power loss of the $\mathrm{HyS}$ and the junction temperature of the SiC MOSFETs, a novel index is proposed to select the optimal prior turn-off period. Based on the HyS power modules, a $5 \mathrm{~kW}$ aircooling voltage source inverter and a $30 \mathrm{~kW}$ water-cooling voltage source inverter were developed and tested to verify the analysis.
\end{abstract}

Index Terms-Hybrid switch, insulated gate bipolar transistors (IGBTs), metal-oxide semiconductor field-effect transistors (MOSFETs), silicon carbide (SiC).

\section{INTRODUCTION}

$\mathrm{I}^{\mathrm{n}}$ the past decades, the Silicon (Si) Insulated Gate Bipolar Transistor (IGBT) has been widely used in many engineering applications such as renewable energy systems, utility power systems and transportation drives [1]. As the growth of the electric cars and the high-speed trains, the highly integrated power converters with more and more high switching frequency are now demanded. However, the long turn-off period induced from the minority carriers recombination namely the tail current severely restricts the switching frequency of the Si IGBT [2].

The Silicon Carbide $(\mathrm{SiC})$ devices are the attractive alternatives because of their potential of high switching frequency [3] and high junction temperature [4]. Among them, the $\mathrm{SiC}$ Metal-Oxide Semiconductor Field-Effect Transistor (MOSFET) is the most promising device to replace the Si IGBT for its high blocking voltage and compatible gate driver design [5]. Unfortunately, the SiC MOSFET is still under development and it is too expensive to be large scale adopted [6].

Manuscript received November 10, 2018. This work was supported in part by the National Key Research and Development Program of China (2016YFB0100600).

The authors are with the Institute of Electrical Engineering, Chinese Academy of Sciences, Beijing 100190, China and the University of Chinese Academy of Sciences, Beijing 100049, China (e-mail: lilei@mail.iee.ac.cn; npq@mail.iee. ac.cn; wxh@mail.iee.ac.cn; zhangdong@mail.iee.ac.cn).

Digital Object Identifier 10.24295/CPSSTPEA.2018.00029
The concept of the hybrid switch (HyS) was first proposed in 1993 [7]. With the help of the paralleled MOSFETs, zerovoltage switch (ZVS) of the IGBTs [8] is realized. Thus, the switching loss is reduced and the switching frequency is improved. Compared with the $\mathrm{Si}$ counterparts, the $\mathrm{SiC}$ MOSFETs have lower on-resistance [9] and lower reverse recovery energy [10]. Thus, better performance of the HyS can be achieved.

The HySs consisting of the paralleled Si IGBTs and the $\mathrm{SiC}$ MOSFETs have been investigated before [11]-[19]. It was demonstrated that the HySs can perform lower switching loss compared to the Si IGBTs and lower cost compared to the SiC MOSFETs [11], [12]. However, the reported HySs are commonly based on the discrete semiconductors and the parasitic inductors of the connection severely restrict their performance [13], [14]. A $6.5 \mathrm{kV} / 40$ A HyS power module was developed in [15]. The HyS power module contained only one switch and only the double pulse test was conducted. Possible gate sequences for the HySs were evaluated and the optimal gate sequence was chosen by solely considering the power loss of the HySs [16]-[18]. There is large thermal stress on the $\mathrm{SiC}$ MOSFETs within the HySs because the entire load current is conducted through the SiC MOSFETs during the switching transients. A thermal balance control mode and a currentdependent switching strategy was presented in [18] and [19] respectively to keep the reliable operation of the SiC MOSFETs.

Improved from the previous studies, in this paper, a compact HyS half-bridge power module, rated at $1200 \mathrm{~V} / 200 \mathrm{~A}$, was fabricated to suppress the influence of the parasitic inductors and to fully utilize the advantages of the HyS. Si/SiC current ratio is 4:1. An electrothermal model of the HyS was set up in LTspice to determine the suitable gate sequence for the HyS. Considering the power loss of the HyS and the junction temperature of the SiC MOSFETs, a novel index is proposed to select the prior turn-off period between the turn-off gate signals of the Si IGBTs and the SiC MOSFETs. Utilizing the HyS power modules, a $5 \mathrm{~kW}$ air-cooling voltage source inverter and a $30 \mathrm{~kW}$ water-cooling voltage source inverter were developed and tested to verify the analysis.

\section{Hybrid Switch Power Module}

Fig. 1 depicts the layout of the HyS half-bridge power module. Each HyS consists of one SiC MOSFET (CPM21200-0025B, $1200 \mathrm{~V} / 50 \mathrm{~A}$ at $100{ }^{\circ} \mathrm{C}$ ) and two Si IGBTs (IRG8CH97K10F, $1200 \mathrm{~V} / 100 \mathrm{~A}$ at $100{ }^{\circ} \mathrm{C}$ ). $\mathrm{Si} / \mathrm{SiC}$ current 


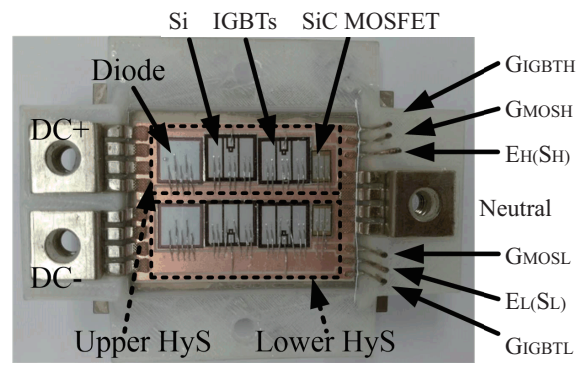

Fig. 1. Layout of the HyS power module.

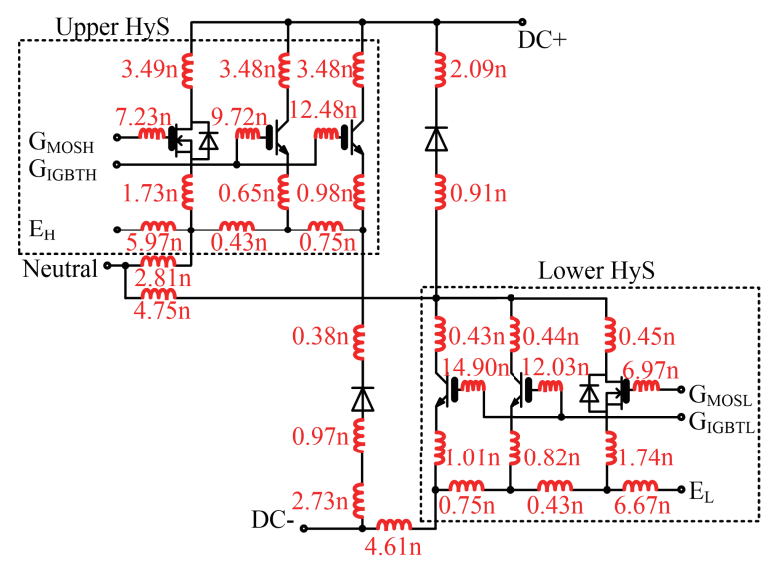

(a)

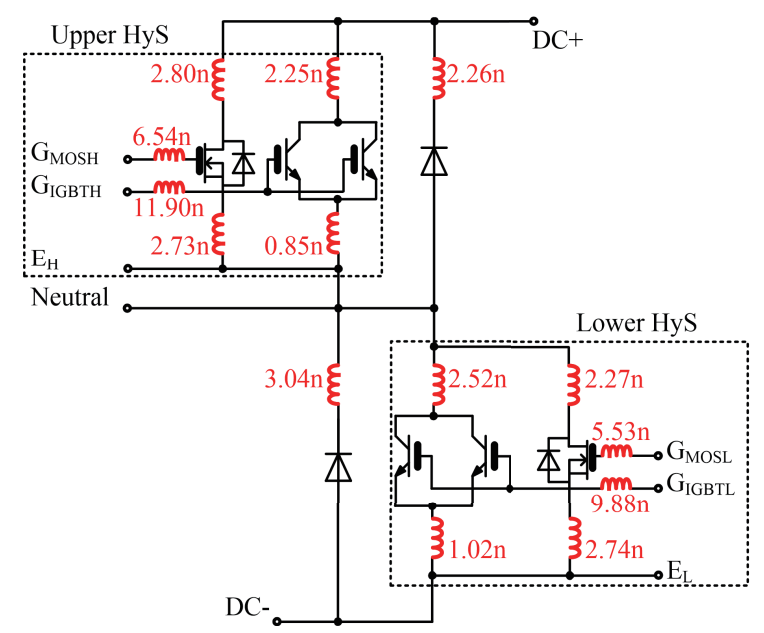

(b)

Fig. 2. Parasitic inductance of the HyS power module. (a) Parasitic inductance extracted by Ansys Q3D. (b) Simplified parasitic inductance.

ratio is 4:1. To reduce the cost, a Si PiN Diode (IRD3CH82DB6, $1200 \mathrm{~V} / 200 \mathrm{~A}$ at $100{ }^{\circ} \mathrm{C}$ ) is paralleled to the HyS. The Si IGBTs and the SiC MOSFET are separately controlled. Power terminals (DC+, DC-, and Neutral) and gate terminals (GIGBTH, GMOSH, EH, GIGBTL, GMOSL, and EL) are bonded to Direct-Bond-Copper (DBC) with ultrasonic method to form large contact areas. Si IGBTs collectors, Si Diode cathode and SiC MOSFET drain are soldered DBC. DBC patterns are designed as compact as possible to reduce the commutation path.
TABLE I

HyS Power Module Packaging Materials

\begin{tabular}{lc}
\hline \hline Part & Specifications \\
\hline $\begin{array}{l}\text { Baseplate } \\
\text { Substrate }\end{array}$ & $\begin{array}{c}\text { Aluminum Silicon Carbide (AlSiC), } 3 \mathrm{~mm} \text { thickness } \\
\text { Aluminum Nitride }(\mathrm{AlN}) \mathrm{DBC} \text { with } \mathrm{Cu} / \mathrm{AlN} / \mathrm{Cu} \\
\text { thickness } 0.2 \mathrm{~mm} / 0.4 \mathrm{~mm} / 0.2 \mathrm{~mm}\end{array}$ \\
$\begin{array}{l}\text { Die solder } \\
\text { Power bonding }\end{array}$ & Au80Sn $20,280^{\circ} \mathrm{C}$ melting point \\
wire & SiC MOSFET, 6 parallel wires for Si IGBTs and 6 \\
& parallel wires for Si Diode \\
Gate terminal & $1 \mathrm{~mm}$ diameter copper pin \\
Power terminal & $0.8 \mathrm{~mm}$ thick copper terminal \\
Encapsulation & Nusil R-2188 \\
Housing & ABS, $1.5 \mathrm{~mm}$ thickness, $82 \mathrm{~mm} \times 64 \mathrm{~mm} \times 6 \mathrm{~mm}$ \\
\hline \hline
\end{tabular}

\section{A. Parasitic Inductance of the HyS Power Module}

The parasitic inductance of the HyS power module was extracted by Ansys Q3D. The results are concluded in Fig. 2(a). It is difficult to determine the parasitic inductance between the Si IGBTs and the SiC MOSFET according to the results extracted by Ansys Q3D. Thus, the parasitic inductance was simplified utilizing the method in [20], shown in Fig. 2(b). The total inductance between the Si IGBTs and the SiC MOSFET is less than $10 \mathrm{nH}$, which has little influence on the dynamic current sharing among the devices [13]. As a comparison, the commercial TO-247 packaged devices which were commonly used in the aforementioned studies have more than $15 \mathrm{nH}$ parasitic inductance in power path [21]. With the module design, the parasitic inductance is decreased a lot.

\section{B. Thermal Resistance of the Chips Within the HyS Power Module}

The packaging materials of the HyS power module are listed in TABLE I. A thermal resistance test system was built to measure the chip to case thermal resistance of the dies [22]. The linear superposition principle is adopted to evaluate the thermal coupling between the different chips and the junction temperature of the chips can be expressed as a thermal resistance matrix,

$$
\begin{gathered}
\left(\begin{array}{c}
T_{j \mathrm{Dided} H} \\
T_{j, \mathrm{IGBTH}} \\
T_{j, \text { MOSH }} \\
T_{j, \text { Didel }} \\
T_{j, \text { IGBTL }} \\
T_{j, \text { MOSL }}
\end{array}\right)=\left(\begin{array}{l}
T_{j, 1} \\
T_{j, 2} \\
T_{j, 3} \\
T_{j, 4} \\
T_{j, 5} \\
T_{j, 6}
\end{array}\right)=\left(\begin{array}{llllll}
R_{11} & R_{12} & R_{13} & R_{14} & R_{15} & R_{16} \\
R_{21} & R_{22} & R_{23} & R_{24} & R_{25} & R_{26} \\
R_{31} & R_{32} & R_{33} & R_{34} & R_{35} & R_{36} \\
R_{41} & R_{42} & R_{43} & R_{44} & R_{45} & R_{46} \\
R_{51} & R_{52} & R_{53} & R_{54} & R_{55} & R_{56} \\
R_{61} & R_{62} & R_{63} & R_{64} & R_{65} & R_{66}
\end{array}\right) \cdot\left(\begin{array}{l}
P_{1} \\
P_{2} \\
P_{3} \\
P_{4} \\
P_{5} \\
P_{6}
\end{array}\right) \\
\left(\begin{array}{cccccccc}
R_{11} & R_{12} & \cdots & R_{16} \\
R_{21} & R_{22} & \cdots & R_{26} \\
\vdots & \vdots & \ddots & \vdots \\
R_{61} & R_{62} & \cdots & R_{66}
\end{array}\right)=\left(\begin{array}{lllllll}
0.48 & 0.14 & 0.02 & 0.09 & 0.12 & 0.02 \\
0.05 & 0.33 & 0.06 & 0.02 & 0.03 & 0.03 \\
0.02 & 0.18 & 0.95 & 0.02 & 0.09 & 0.15 \\
0.12 & 0.09 & 0.02 & 0.50 & 0.12 & 0.02 \\
0.02 & 0.05 & 0.02 & 0.05 & 0.32 & 0.08 \\
0.02 & 0.12 & 0.15 & 0.02 & 0.21 & 0.93
\end{array}\right)
\end{gathered}
$$


where $T_{j, i}(i=1-6)$ are the junction temperatures of the chips, $P_{i}(i=1-6)$ are the power losses of the chips, $R_{i i}(i=1-6)$ are the chip to case thermal resistance of the dies and $R_{i k}(i, k=1-6$ and $i \neq k$ ) describe the junction temperatures rising because of thermal coupling. The two Si IGBTs are treated as one chip to simplify the tests and the analyses. The test results are concluded in (2).

\section{Electrothermal Model of the Hybrid Switch}

There are four kinds of semiconductors within a HyS, namely Si PiN Diode, Si IGBT, SiC MOSFET and the body diode of the $\mathrm{SiC}$ MOSFET, which is also a PiN Diode.

\section{A. Electrothermal Model of the HyS}

Fig. 3 demonstrates the circuit representation of the PiN diode model. It is made up of three parts. The first part is based on the finite difference method (FDM) [23] to calculate the excess carrier concentration in the base region under high level injection. $I_{l}$ and $I_{n+l}$ are the boundary conditions to solve the ambipolar diffusion equation. The second part is the model to calculate the quasi-neutral base width. The quasi-neutral base region is divided into $n$ elements with the equal length. The third part is a series of voltage sources representing the diode voltage, where $E_{j A}, E_{r e s}, E_{j D}$, and $E_{S C}$ is the voltage across the $\mathrm{P}+/ \mathrm{N}-$ junction, the voltage across the base region, the voltage across the $\mathrm{N}-/ \mathrm{N}+$ junction, and the voltage across the depletion region respectively. The values of the voltage sources are determined by the excess carrier concentration in the base region. In the simulation, the quasi-neutral base region is separated into 10 elements.

Fig. 4 displays the circuit representation of the SiC MOSFET model.The MOSFET channel current consists of $I_{\text {mosl }}$, conducted through the corners of the MOSFET cells, and $I_{\text {mosh }}$, conducted through the main portion of the MOSFET cells [24]. $R_{d}$ is composed of the $\mathrm{N}$ - base region resistor and the drain contact resistor. $R_{s}$ and $R_{g}$ is the source contact resistor and the gate contact resistor respectively. The switching characteristics of the $\mathrm{SiC}$ MOSFET are described through the gate-source capacitor $C_{g s}$, gate-drain capacitor $C_{g d}$, and drain-source capacitor $C_{d s}$. $C_{g s}$ and $C_{d s}$ are determined by gate-source voltage and drain-source voltage respectively while $C_{g d}$ ane related to both of them. The voltage-controlled capacitors are modeled through a voltagecontrolled voltage source, a normal capacitor, and a currentcontrolled current source [25].

Shown in Fig. 5, the Si IGBT model is the combination of the FDM model and the MOSFET model. The excess carrier concentration in the base region is calculated through the FDM method, and the on-state voltage of the Si IGBT is composed of $E_{j A}, E_{r e s}$, and $E_{S C}$. The switching characteristics of the Si IGBT are described through the gate-emitter capacitor $C_{g e}$, gatecollector capacitor $C_{g c}$, and collector-emitter capacitor $C_{c e}$.

According to the results of the thermal resistance test, the thermal model of the Si IGBT is displayed as Fig. 6 [26]. Junction temperature rise of the Si IGBT is due to the self-heating of the Si IGBT and the thermal coupling between the Si IGBT and the other semiconductors. Thermal model of the Si PiN Diode and the SiC MOSFET can be described using the same circuit.

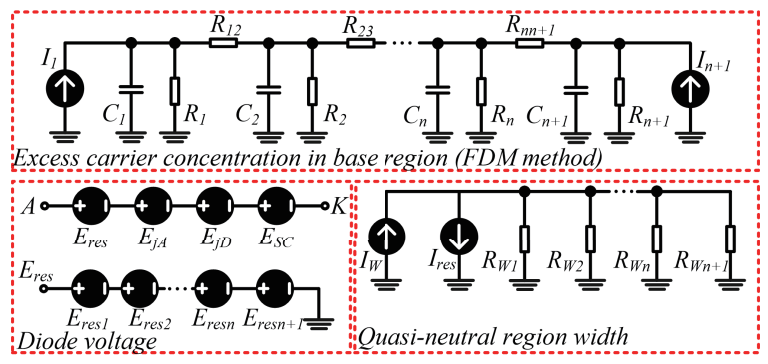

Fig. 3. PiN diode model.
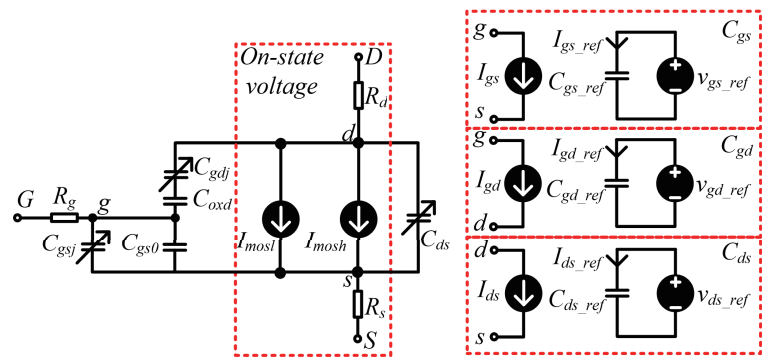

Fig. 4. SiC MOSFET model.

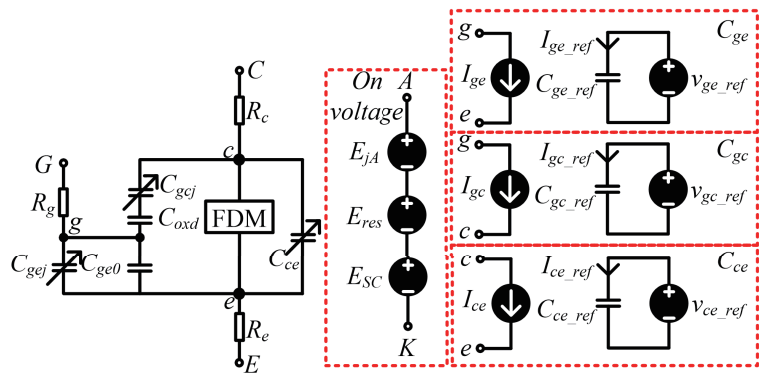

Fig. 5. Si IGBT model.
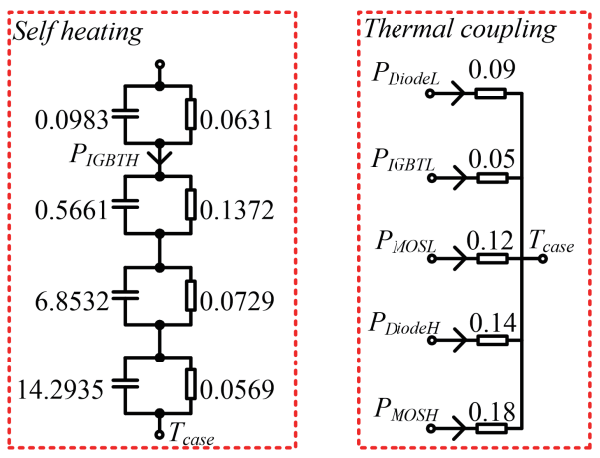

Fig. 6. Thermal model of the Si IGBT.

\section{B. Verification of the Electrothermal Model}

The output characteristics of the semiconductors were tested by the static and dynamic testing system from LEMSYS while the switching characteristics were tested utilizing a double pulse test fixture based on the voltage source inverter in Section V [27].

To carry out tests for the separate semiconductors, several 


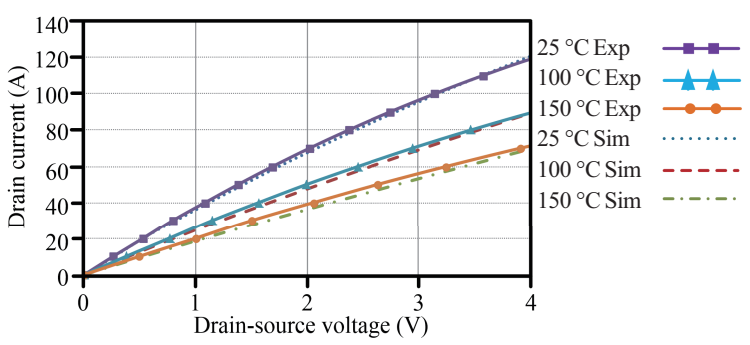

(a)

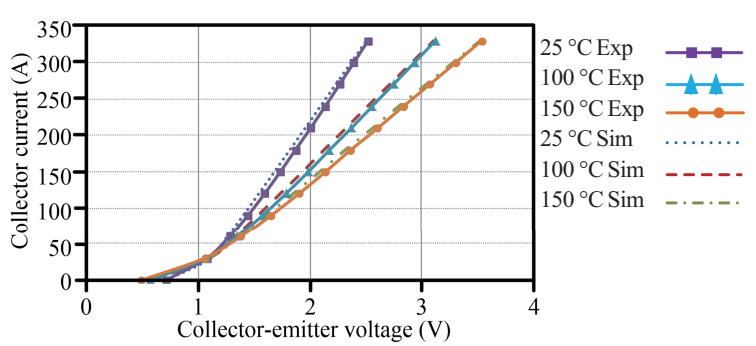

(b)

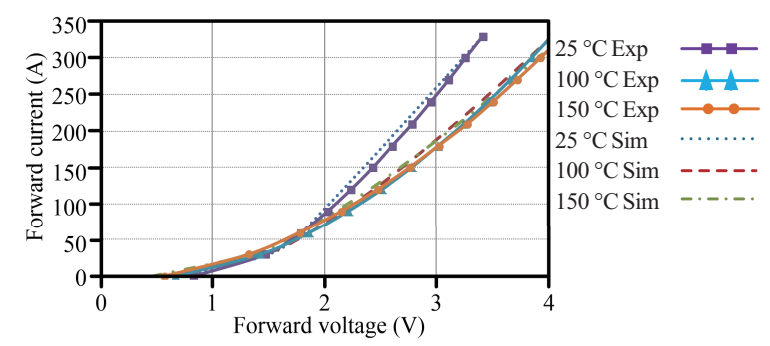

(c)

Fig. 7. Comparison of the experiment and simulation output characteristics. (a) SiC MOSFET. (b) Si IGBT. (c) Si Diode.

HyS power modules were fabricated. All the chips were implemented in the HyS power modules, but only the utilized chips in the corresponding test were connected through the bonding wires. For example, only the Si PiN Diode was connected through the bonding wires to test the output characteristics of the Si PiN Diode. Only the SiC MOSFET and the Si PiN Diode were connected to test the switching characteristics of the SiC MOSFET or the Si PiN Diode. As demonstrated in Fig. 7 and Fig. 8, the output and switching characteristics of the dies predicted by the electrothermal model agree well with the experimental results. Therefore, the electrothermal model can be utilized to determine the gate sequence for the HyS.

\section{Gate Sequence for the Hybrid Switch}

As depicted in Fig. 9, all the gate sequences for the HyS can be described using the prior turn-on period $t_{\text {on_delay }}$ and the prior turn-off period $t_{\text {off_elay }}$.

Collectors of the Si IGBTs and drain of the SiC MOSFET are connected to the same DBC in the HyS power module (shown in Fig. 1). The power loss of the dies cannot be measured separately. Thus, the proposed HyS power module was simulated in LTSpice to find the optimal gate sequence. The simulation circuit is illustrated in Fig. 10. Buck circuit

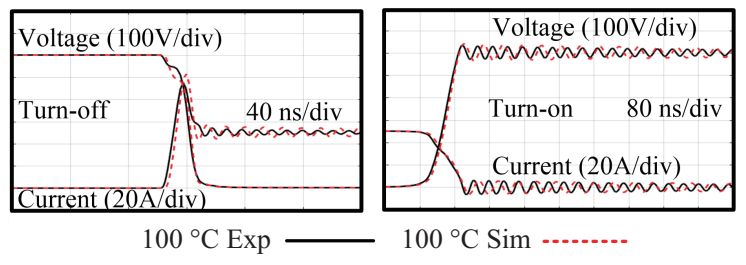

(a)

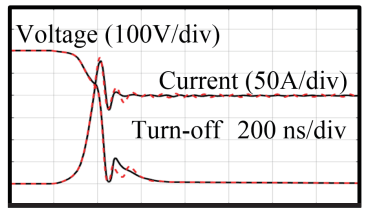

$100{ }^{\circ} \mathrm{C} \operatorname{Exp}$

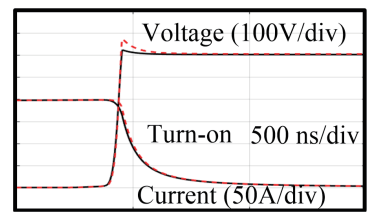

$100{ }^{\circ} \mathrm{C} \mathrm{Sim}$

(b)

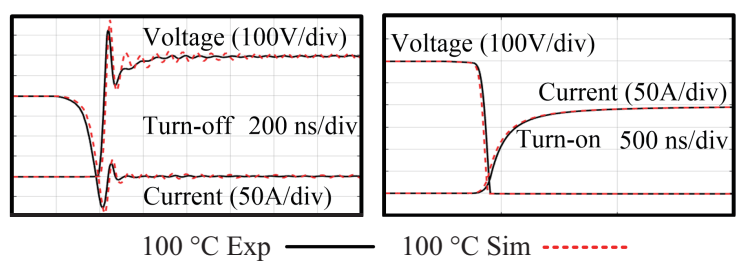

(c)

Fig. 8. Comparison of the experiment and simulation switching characteristics. (a) SiC MOSFET. (b) Si IGBT. (c) Si Diode.

was utilized to set the load current $i_{L}$ and the DC-bus voltage $v_{d c}$. Parasitic inductors were not considered in the simulation. Baseplate temperature was set to be $35{ }^{\circ} \mathrm{C}$. Switching frequency was $50 \mathrm{kHz}$.

Fig. 11 displays the simulation results with $v_{d c}$ of $400 \mathrm{~V}$ and $i_{L}$ of $130 \mathrm{~A}$. It is obvious that non-zero $t_{\text {on delay }}$ cannot bring any more reduction in the HyS power loss. In fact, the SiC MOSFET turns on prior to the Si IGBTs even the gate signals are applied at the same time because of the larger input capacitance of the $\mathrm{Si}$ IGBTs and the time taken to modulate the N-drift region conductivity [28]. Negative $t_{\text {on_delay }}$ is not useful for reducing switching loss but introduces more conduction loss. As for positive $t_{\text {on delay }}$, it eliminates the zero-current turn on of the Si IGBTs and enlarges the switching loss and the conduction loss, shown in Fig. 11(b). $t_{\text {on delay }}$ should remain as 0 .

Fig. 12 illustrates the simulation results with $v_{d c}$ of $400 \mathrm{~V}$ and $i_{L}$ of $130 \mathrm{~A}$ utilizing different $t_{\text {off_delay }}$. As $t_{\text {off_delay }}$ becomes larger, the HyS power loss decreases, but the SiC MOSFET power loss increases. A novel index as in (3) is adopted to determine the suitable $t_{\text {off_delay }}$. It is a characterization of the tradeoff between the HyS power loss reduction, $\Delta$ loss and the SiC MOSFET $T_{j}$ rise, $\Delta T_{j}$,

$$
\text { Index }=\frac{-\Delta \text { loss }}{\Delta t_{\text {off_delay }}} / \frac{\Delta T_{j}}{\Delta t_{\text {off_delay }}}=\frac{-\Delta \text { loss }}{\Delta T_{j}}
$$

Fig. 13 displays the index curve versus $t_{\text {off_delay }}$. The horizontal red line set the $T_{j}$ limit as $150^{\circ} \mathrm{C}$ and the maximum $t_{\text {off delay }}$ is restricted to be 3.5 us (Point C). Within the permissible $t_{\text {off_delay }}$, the index reaches the peak value at 1 us (Point A). 


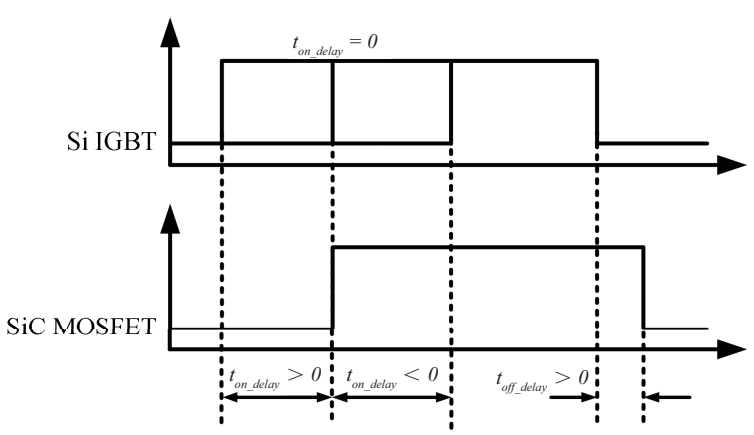

Fig. 9. Gate sequences for the HyS.

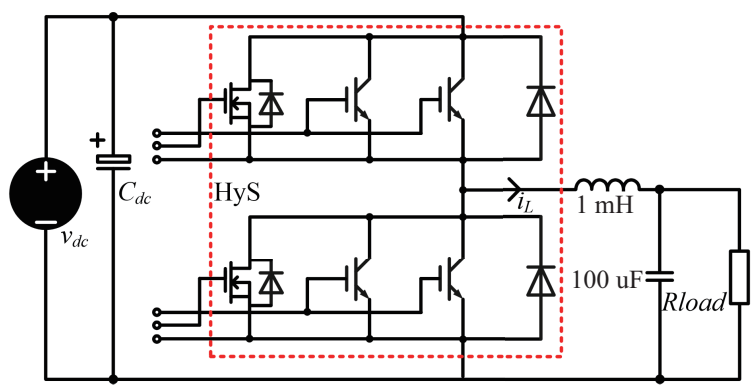

Fig. 10. Schematic of the simulation circuit.

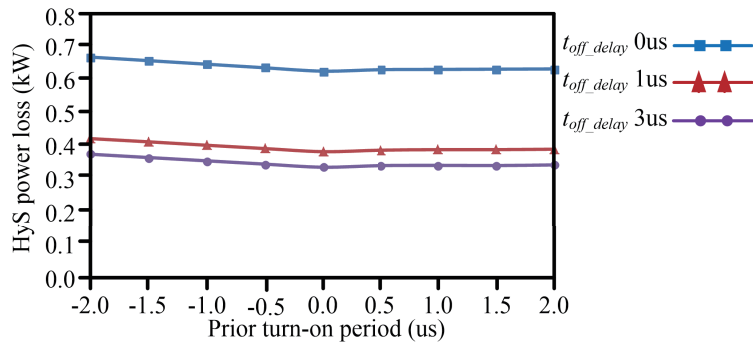

(a)

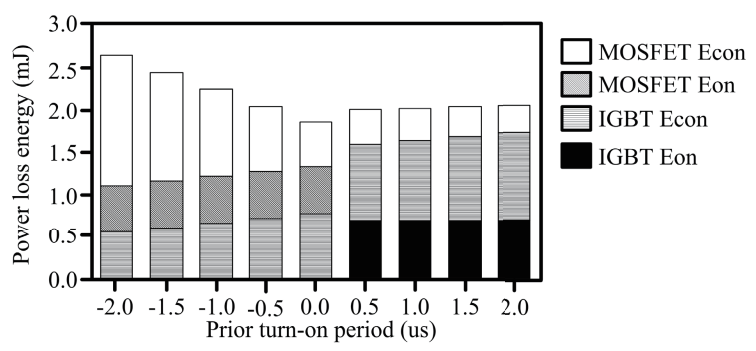

(b)

Fig. 11. Simulation results $\left(v_{d c}=400 \mathrm{~V}, i_{L}=130 \mathrm{~A}\right)$. (a) HyS power loss at different $t_{\text {on_delay }}$ and $t_{\text {off_delay }}$. (b) HyS loss energy distribution at different $t_{\text {on_delay }}$. Econ and Eon are conduction loss and turn-on loss respectively.

Between Point A and Point B (3 us), the HyS power loss can be further reduced, but the $\mathrm{SiC}$ MOSFET $T_{j}$ rise is higher. Beyond Point B, the HyS power loss even starts to increase and drive the index to be negative. Therefore, the optimal $t_{\text {off_elay }}$ is 1 us. Optimal $t_{\text {off_delay }}$ at other operation conditions is concluded in Fig. 14.

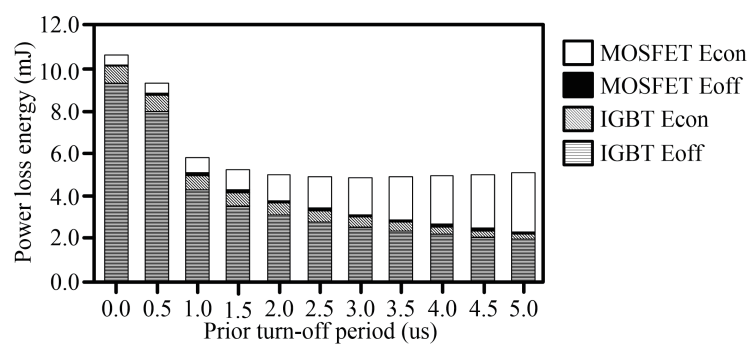

Fig. 12. HyS power loss energy distribution at different $t_{\text {off_delay }}\left(v_{d c}=400 \mathrm{~V}, i_{L}=\right.$ $130 \mathrm{~A})$. Eoff is the turn-off loss.

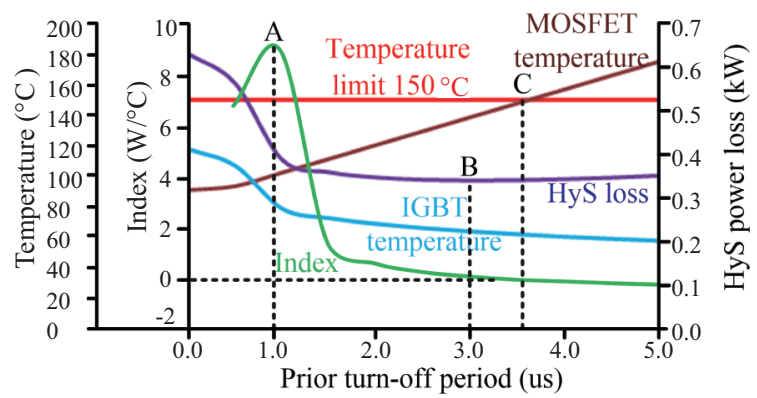

Fig. 13. Index plot to determine the suitable $t_{\text {off_elay }}$.

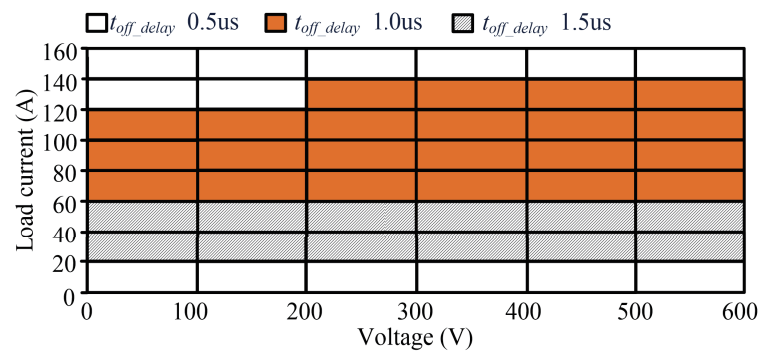

Fig. 14. Optimal prior turn-off period at different operation conditions.

\section{Hybrid Switch Based Voltage Source Inverter}

Utilizing the HyS power modules, a three-phase air-cooling voltage source inverter was set up to verify the analysis, shown in Fig. 15. The inverter was tested in open-loop mode with SVPWM control. The operation parameters are given in TABLE II.

For each HyS, there were two separate gate driver circuits to control the $\mathrm{SiC}$ MOSFET and the Si IGBTs independently. To assure the switching performance, a $2.5 \mathrm{~A}$ peak current optocoupler ACPL-332J from Avago followed by a 9 A peak current push-pull circuit IXDN609SI from IXYS were adopted as the gate driver ICs. $2 \mathrm{~W}$ DC/DC converters MGJ2D242005SC and MGJ2D241509SC were utilized as the gate driver power supply for the SiC MOSFET and the Si IGBTs respectively. Three $30 \Omega$ chip resistors and three $15 \Omega$ chip resistors, all in 2512 with $2 \mathrm{~W}$ rated power, were paralleled to form the gate resistors for the SiC MOSFET and the Si IGBTs respectively. During the turn off transient of SiC MOSFET, a fault turn-on of Si IGBTs may occur due to the fast rising collector-emitter voltage charges Miller 

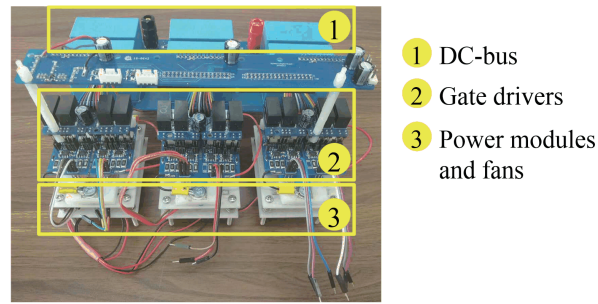

(a)

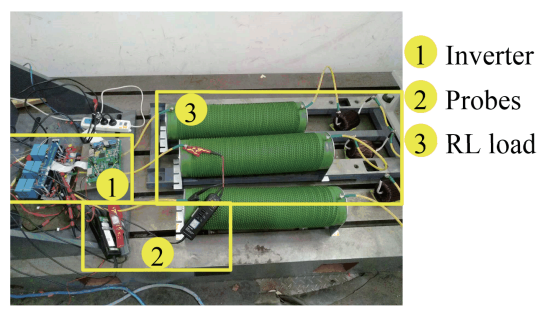

(b)

Fig. 15. Three-phase voltage source inverter. (a) Inverter prototype. (b) Test platform.

TABLE II

Three-Phase Voltage Source Inverter Operation Parameters

\begin{tabular}{ll}
\hline \hline Parameter & \multicolumn{1}{c}{ Value } \\
\hline Input DC-bus voltage & $400 \mathrm{~V}$ \\
Switching frequency & 5 to $30 \mathrm{kHz}$ \\
Modulation ratio & 0.43 \\
RL Load & $3.0 \Omega / 0.5 \mathrm{mH}$ \\
Fundamental phase current amplitude & $33 \mathrm{~A}$ \\
Fundamental output frequency & $50 \mathrm{~Hz}$ \\
Rated output power & $5 \mathrm{~kW}$ \\
\hline \hline
\end{tabular}

capacitors [16]. Thus, the active miller clamp function of ACPL332J was utilized to depress the miller effect. Besides, the desaturation protection method was utilized by monitoring the on-state drain-source voltage of the SiC MOSFET to avoid shooting through fault.

The gate driver is a four-layer printed circuit board (PCB). In each gate loop, the emitter lines and gate lines are routed at different layers. The DC-DC converters are separately placed at another PCB which connects the gate drive board via the pins. Through such a design, the gate loop is perpendicular to the power loop of the HyS module. The trenches are dug everywhere isolation is needed to ensure the safety. The gate driver board is soldered to the gate pins of the HyS power module to minimize the parasitic inductance within gate loop. Details of the gate driver can be found in [27].

Test procedures are as follows. At first, only the Si IGBTs in the HyS power modules were switched. The SiC MOSFETs were kept in off state. The switching frequency was $5 \mathrm{kHz}$. Then the gate sequence with the fixed $t_{\text {on delay }}$ of 1 us (Option 2 ) and -1 us (Option 3 ) respectively and the fixed $t_{\text {off_delay }}$ of 0.5 us was applied. The switching frequency remained

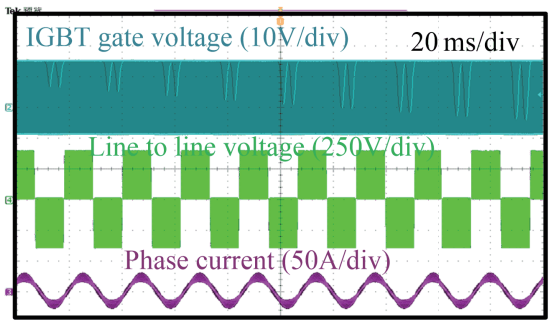

(a)

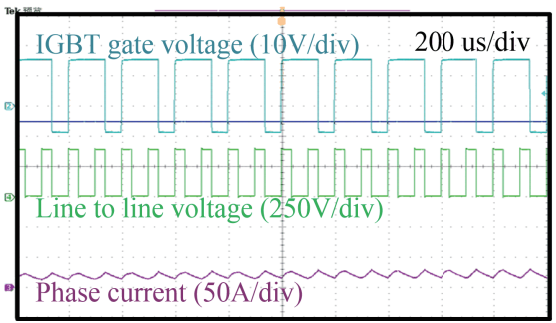

(b)

Fig. 16. Experimental waveforms of the three-phase voltage source inverter. Only the Si IGBTs were switched. (a) Gate voltage, line to line voltage and phase current waveforms. (b) Zoom-in waveforms. Switching frequency was $5 \mathrm{kHz}$. (200 us/div)

as $5 \mathrm{kHz}$. At last, the gate sequence with non-constant $t_{\text {off delay }}\left(\right.$ Option 1) was utilized. $t_{\text {on delay }}$ was set to be 0 us. The switching frequency was $5 \mathrm{kHz}, 10 \mathrm{kHz}$, and $30 \mathrm{kHz}$ respectively. The gate sequences were realized through the PWM module of the DSP F28335. Experimental waveforms are demonstrated from Fig. 16 to Fig. 19. The gate voltages were obtained at the lower leg of the middle HyS power module and the positive phase current flowed through the HyS.

Fig. 16 displays the experimental waveforms of the threephase voltage source inverter. Only the Si IGBTs within the HyS power modules were switched. Gate voltage of the $\mathrm{SiC}$ MOSFETs was kept at $-5 \mathrm{~V}$ to disable the switches. There were almost no disturbances on the gate voltage of the $\mathrm{SiC}$ MOSFETs at the switching transients of the Si IGBTs. Switching frequency was $5 \mathrm{kHz}$. PT1000 thermistor was attached to the baseplate of the middle HyS power module. Baseplate temperature was utilized as an indicator of the HyS power loss. Air flow of the fans is $0.5 \mathrm{~m}^{3} / \mathrm{min}$. As the output power increased from $1 \mathrm{~kW}$ to $5 \mathrm{~kW}$, the baseplate temperature rose from $25^{\circ} \mathrm{C}$ to $50^{\circ} \mathrm{C}$.

Fig. 17 displays the experimental waveforms of the threephase voltage source inverter utilizing the gate sequence Option 2 with the fixed $t_{\text {on delay }}$ of 1 us and the fixed $t_{\text {off delay }}$ of 0.5 us. Si IGBTs were turned on prior to the SiC MOSFET. With a positive $t_{\text {off_delay }}$, the Si IGBTs are expected to be turned off prior to the SiC MOSFET. However, a short $t_{\text {off_elay }}$ may be not enough. There are two reasons for the increase of the gate voltage of the Si IGBTs (shown in Fig. 17(d)). The first one is the miller effect. Even though an active miller clamp circuit was utilized, the circuit was not supposed to work when the gate voltage of the Si IGBTs was still high. That is, a short 


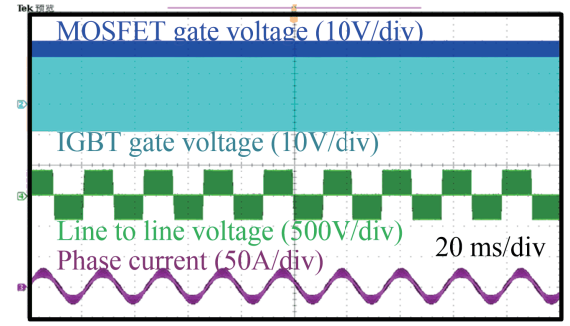

(a)

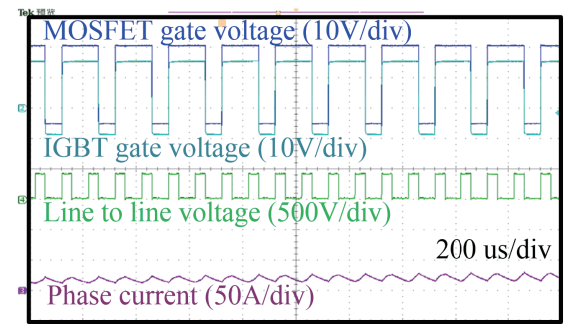

(b)

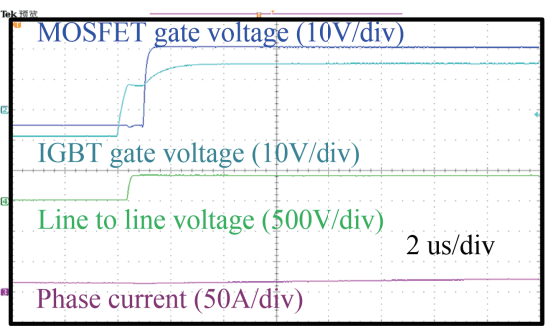

(c)

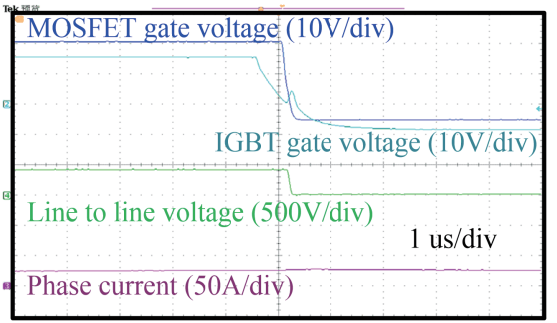

(d)

Fig. 17. Experimental waveforms of the three-phase voltage source inverter. Gate sequence Option 2 with the fixed $t_{o n \text { delay }}$ of 1 us and the fixed $t_{\text {off delay }}$ of 0.5 us was applied. (a) Gate voltages, line to line voltage and phase current waveforms. (b) Zoom-in waveforms. Switching frequency was $5 \mathrm{kHz}$. (200 us/div) (c) Zoom-in waveforms at the turn-on instant. (d) Zoom-in waveforms at the turn-off instant. The Si IGBTs turned on again at the turn-off moment of the SiC MOSFET because $t_{\text {off delay }}$ was small for the load current.

$t_{\text {off_delay }}$ may disable the function of miller clamp circuit. The second reason is that the depletion layer expands toward the collector within the N- region of the Si IGBTs, which not only drives the excess carriers away from the $\mathrm{N}$ - drift region but also makes an accumulation layer form under the $\mathrm{P}+$ collector. Hereby, both collector current and gate voltage rise. Both phenomena can not be avoided and can become severer at a larger current. A longer $t_{\text {off delay }}$ is helpful for suppressing the effects.

The baseplate temperature rose from $25{ }^{\circ} \mathrm{C}$ to $35^{\circ} \mathrm{C}$ as the output power increased from $1 \mathrm{~kW}$ to $5 \mathrm{~kW}$. Better performance of the HyS compared with the pure Si IGBTs was observed.

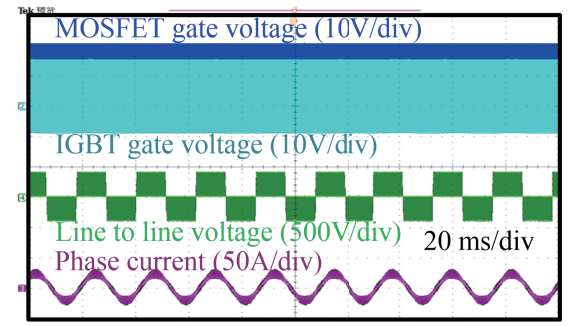

(a)

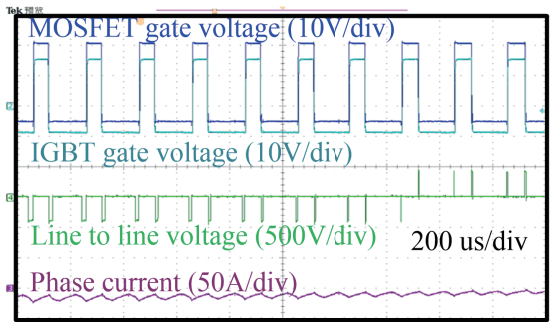

(b)

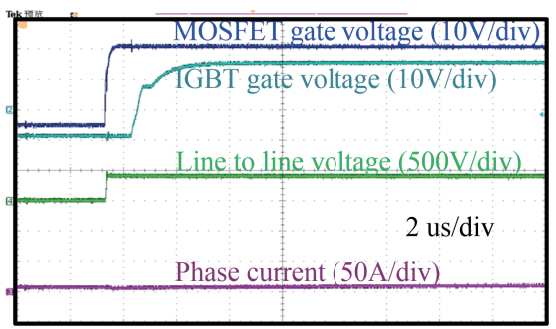

(c)

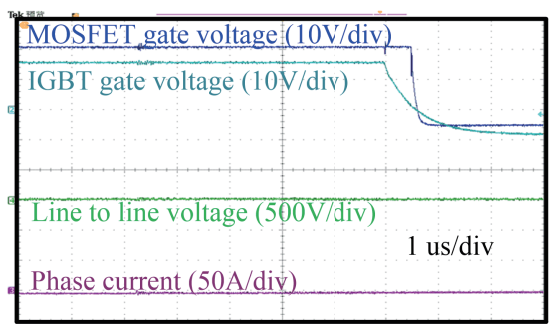

(d)

Fig. 18. Experimental waveforms of the three-phase voltage source inverter. Gate sequence Option 3 with the fixed $t_{\text {on delay }}$ of -1 us and the fixed $t_{\text {off delay }}$ of 0.5 us was applied. (a) Gate voltages, line to line voltage and phase current wave-forms. (b) Zoom-in waveforms. Switching frequency was $5 \mathrm{kHz}$. (200 us/div) (c) Zoom-in waveforms at the turn-on instant. (d) Zoom-in waveforms at the turn-off instant. The Si IGBTs did not turn on again at the turn-off moment of the SiC MOSFET because $t_{\text {off_elay }}$ was long enough for the load current (Load current was negative and did not flow through the HyS).

As shown in Fig. 18, compared with the gate sequence Option 2, the gate sequence Option 3 reduces the turn-on loss. Thus, a lower baseplate temperature as $30{ }^{\circ} \mathrm{C}$ was obtained at the output power of $5 \mathrm{~kW}$.

Fig. 19 displays the experimental waveforms utilizing the gate sequence Option 1. The lowest temperature was observed because it fully utilized the potential of the HyS. As switching frequency increased to $30 \mathrm{kHz}$, the baseplate temperature was $67{ }^{\circ} \mathrm{C}$ at the rated output power. Replacing the fans with the water-cooling plates, the inverter was tested at $30 \mathrm{~kW} / 30 \mathrm{kHz}$, 


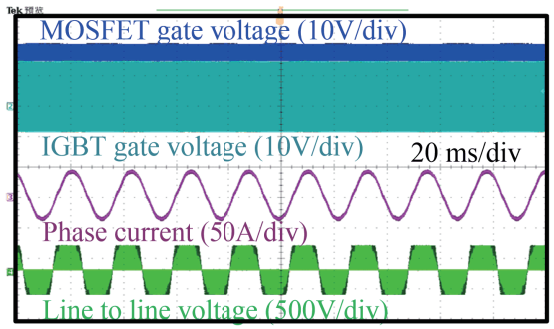

(a)

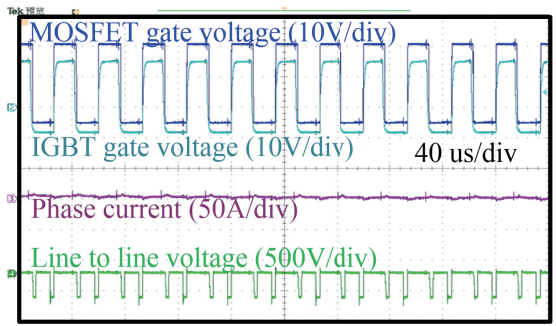

(b)

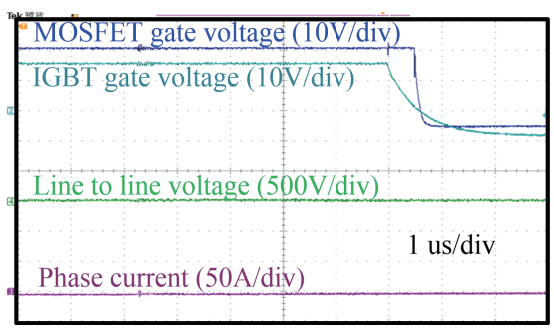

(c)

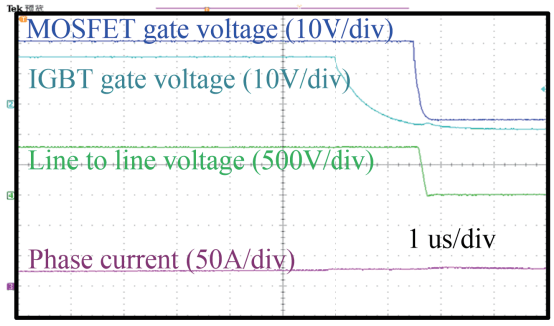

(d)

Fig. 19. Experimental waveforms of the three-phase voltage source inverter. Gate sequence Option 1 with the non-constant $t_{\text {off_delay }}$ was applied. (a) Gate voltages, line to line voltage and phase current waveforms. (b) Zoom-in waveforms. Switching frequency was $30 \mathrm{kHz}$ (40 us/div). (c) Zoom-in waveforms at the turn-off instant. Small $t_{\text {off delav }}(0.5$ us) was utilized because of the little load current. (d) Zoom-in waveforms at the turn-off instant. Large $t_{\text {off delay }}(1.5$ us) was utilized because the load current became larger.

shown in Fig. 20. Inlet cooling temperature was set to be $30^{\circ} \mathrm{C}$.

\section{CONCLUSION}

A Si IGBT/SiC MOSFET HyS power module was packaged. The $\mathrm{Si} / \mathrm{SiC}$ current ratio is $4: 1$. A novel index is proposed to determine the optimal prior turn-off period of the Si IGBTs. Compared with the pure Si IGBTs, the HyS can operate at a higher switching frequency with the reduced power loss. A $5 \mathrm{~kW}$ air-cooling voltage source inverter and a $30 \mathrm{~kW}$ water-cooling voltage source inverter were built for verification. The main features of the paper are as follows.

(1) HyS phase-leg power modules were fabricated and fully

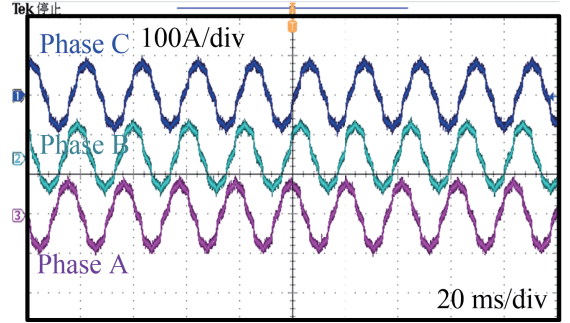

(a)

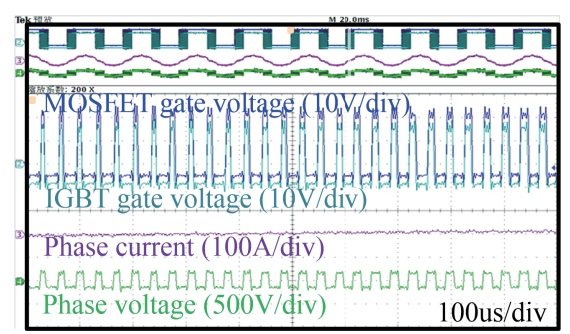

(b)

Fig. 20. Experimental waveforms of the voltage source inverter $(30 \mathrm{~kW} / 30 \mathrm{kHz})$. (a)Three phase current. Amplitude of the current was 100 A. (b) Zoom-in waveforms. Switching frequency was $30 \mathrm{kHz}$. DC bus voltage was $550 \mathrm{~V}$.

tested for the first time.

(2) A method to select the optimal gate sequence for the HyS is presented.

\section{REFERENCES}

[1] U. M. Choi, F. Blaabjerg, S. Jorgensen, S. Munk-Nielsen, and B. Rannestad, "Reliability improvement of power converters by means of condition monitoring of IGBT modules," IEEE Trans. Power Electron., vol. 32, no. 10, pp. 7990-7997, Oct. 2017.

[2] S. Dieckerhoff, S. Bernet, and D. Krug, "Power loss-oriented evaluation of high voltage IGBTs and multilevel converters in transformerless traction applications," IEEE Trans. Power Electron., vol. 20, no. 6, pp. 1328-1336, Nov. 2005.

[3] B. Rannestad, A. E. Maarbjerg, K. Frederiksen, S. Munk-Nielsen, and K. Gadgaard, "Converter monitoring unit for retrofit of wind power converters," IEEE Trans. Power Electron., vol. PP, no. 99, pp. 1-1, May. 2017.

[4] Z. Xu, D. Jiang, M. Li, P. Ning, F. F. Wang, and Z. Liang, "Development of Si IGBT phase-leg modules for operation at $200{ }^{\circ} \mathrm{C}$ in hybrid electric vehicle applications," IEEE Trans. Power Electron., vol. 28, no. 12, pp. 5557-5567, Dec. 2013.

[5] S. T. Kong, L. K. Ngwendson, M. Sweet, and D. Kumar, "Turn-off behavior of $1.2 \mathrm{kV} / 25$ A NPT-CIGBT under clamped inductive load switching," IEEE Trans. Power Electron., vol. 24, no. 4, pp. 11001106, Apr. 2009.

[6] P. Ning, L. Li, X. Wen, and H. Cao, "A hybrid Si IGBT and SiC MOSFET module development," CES Transactions on Electrical Machines and Systems, vol. 1, no. 4, pp. 360-366, Dec. 2017.

[7] Y. Jiang, G. C. Hua, E. Yang, and F. C. Lee, "Soft-switching of IGBTs with the help of MOSFETs in bridge-type converters," in Power Electronics Specialists Conference, 1993, pp. 151-157.

[8] Q. Jinrong, A. Khan, and I. Batarseh, "Turn-off switching loss model and analysis of IGBT under different switching operation modes," in Industrial Electronics, Control, and Instrumentation, 1995, pp. 240245.

[9] Y. C. Liang, R. Oruganti, and T. B. Oh, "Design considerations of power MOSFET for high frequency synchronous rectification," IEEE Trans. Power Electron., vol. 10, no. 3, pp. 388-395, May. 1995.

[10] X. Yuan, S. Walder, and N. Oswald, "EMI generation characteristics 
of $\mathrm{SiC}$ and $\mathrm{Si}$ diodes: influence of reverse-recovery characteristics," IEEE Trans. Power Electron., vol. 30, no. 3, pp. 1131-1136, Mar. 2014.

[11] M. Rahimo et al., "Characterization of a silicon IGBT and silicon carbide MOSFET cross-switch hybrid," IEEE Trans. Power Electron., vol. 30, no. 9, pp. 4638-4642, Sept. 2015.

[12] H. Qin, D. Wang, Y. Zhang, D. Fu, and C. Zhao, "Characteristics and switching patterns of $\mathrm{Si} / \mathrm{SiC}$ hybrid switch," in 2017 International Exhibition and Conference for Power Electronics, Intelligent Motion, Renewable Energy and Energy Management, 2017, pp. 1-6.

[13] G. Ortiz, C. Gammeter, J. W. Kolar, and O. Apeldoorn, "Mixed MOSFET-IGBT bridge for high-efficient medium-frequency dualactive-bridge converter in solid state transformers," in 2013 IEEE 14th Workshop on Control and Modeling for Power Electronics (COMPEL), 2013, pp. 1-8.

[14] A. Deshpande and F. Luo, "Comprehensive evaluation of a siliconWBG hybrid switch," in 2016 IEEE Energy Conversion Congress and Exposition (ECCE), 2016, pp.1-8.

[15] J. He, R. Katebi, and N. Weise, "A current-dependent switching strategy for si/sic hybrid switch-based power converters," IEEE Trans. Ind. Electron., vol. 64, no. 10, pp. 8344-8352, Oct. 2017.

[16] J. Wang, Z. Li, X. Jiang, C. Zeng, and Z. Shen, "Gate control optimization of $\mathrm{Si} / \mathrm{SiC}$ hybrid switch for junction temperature balance and power loss reduction," IEEE Trans. Power Electron., to be published.

[17] A. Deshpande and F. Luo, "Practical design considerations for a Si IGBT + SiC MOSFET hybrid switch: Parasitic interconnect influences, cost and current ratio optimization," IEEE Trans. Power Electron., to be published.

[18] Q. X. Guan et al., "An extreme high efficient three-level active neutral-point-clamped converter comprising $\mathrm{SiC} \& \mathrm{Si}$ hybrid power stage," IEEE Trans. Power Electron., vol. PP, no. 99, pp. 1-1, Dec. 2017.

[19] X. Song, A. Q. Huang, M. C. Lee, and C. Peng, "High voltage Si/ SiC hybrid switch: An ideal next step for SiC," in 2015 IEEE 27th International Symposium on Power Semiconductor Devices \& IC's (ISPSD), 2015, pp. 289-292.

[20] Z. Duan, T. Fan, X. Wen, and D. Zhang, "Improved SiC power MOSFET model considering nonlinear junction capacitances," IEEE Trans. Power Electron., vol. 33, no. 3, pp. 2509-2517, Dec. 2017.

[21] C. Chen, Y. Chen, Y. Li, Z. Huang, T. Liu, and Y. Kang, "An SiC-based half-bridge module with an improved hybrid packaging method for high power density applications," IEEE Trans. Ind. Electron., vol. 64, no. 11 , pp. 8980-8991, Nov. 2017.

[22] L. Li et al., "Temperature dependency of the on-state voltage of IGBT and its application in thermal resistance test," in 2018 IEEE Applied Power Electronics Conference and Exposition (APEC), 2018, pp. 2290-2296.

[23] Buiatti, G.M., F. Cappelluti, and G. Ghione. "Power PiN diode model for PSPICE simulations." in Twentieth Annual IEEE Applied Power Electronics Conference and Exposition, 2005.

[24] Ty R. McNutt, A. R. Hefner, H. A. Mantooth, D. Berning, and S. Ryu, "Silicon carbide power MOSFET model and parameter extraction sequence," IEEE Trans. Power Electron., vol. 22, no. 2, pp. 353-363, Mar. 2017.

[25] H. Li et al., "A non-segmented pspice model of SiC MOSFET with temperature-dependent parameters," IEEE Trans. Power Electron., to be published.

[26] Transient Dual Interface Test Method for the Measurement of the Thermal Resistance Junction to Case of Semiconductor Devices with Heat Flow Trough a Single Path, JESD51-14, Nov. 2010.

[27] L. Li, P. Ning, X. Wen, Y. Bian, and D. Zhang, "Gate drive design for a hybrid Si IGBT/SiC MOSFET module," in 2018 IEEE Workshop on Wide Bandgap Power Devices and Applications in Asia (WiPDA Asia 2018), 2018.

[28] B. J. Baliga, "Insulated Gate Bipolar Transistors," in Fundamental of power semiconductor devices, 1st ed, pp. 856-876.

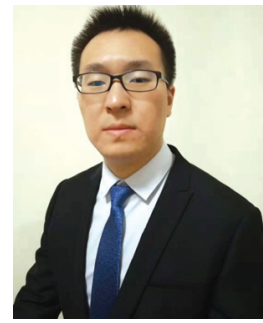

Lei $\mathbf{L i}$ was born in Shanxi, China, in 1992. He received the B.S. degree in electrical engineering from Beijing Institute of Technology, Beijing, China, in 2014.

Since 2014, he has been working toward the Ph.D. degree at the Institute of Electrical Engineering, Chinese Academy of Sciences, Beijing, China. His research interests include power device packaging and reliability, power device modeling, and high density converter design.

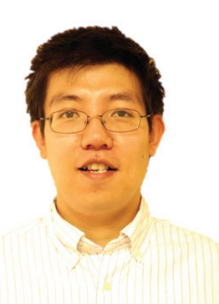

Puqi Ning received the B.S. and M.S. degrees in electrical engineering from Tsinghua University, Beijing, China, in 2004, and 2006, respectively and the Ph.D. degree from electrical engineering of Virginia Tech, Blacksburg, US in 2010

From 2010 to 2013, he was with Oak National Laboratory, Knoxville, TN, USA. Since 2013, He is full professor in Institute of Electrical Engineering, Chinese Academy of Sciences. Dr. Ning has been involved in high temperature packaging and high density converter design for more than 10 years.

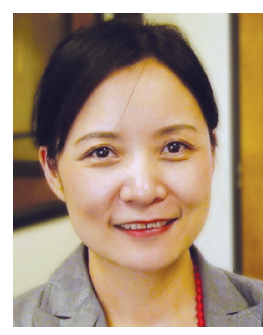

Xuhui Wen received her B.S, M.S and Ph.D. degree in electrical engineering from Tsinghua University, Beijing, China, in 1984, 1989, and 1993 respectively.

Since 1993, she has been in the Institute of Electrical Engineering, Chinese Academy of Sciences, Beijing, China, where she became an Associate Professor in 1996 and a Professor in 1999. From 2004 to 2005, she was a Visiting Researcher with the Ohio State University. Dr. Wen has been involved in high power density electrical drive and generation especially for electric vehicle application for more than 20 years.

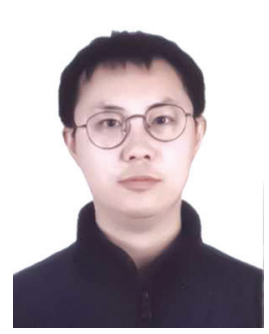

Dong Zhang received the B.S. and M.S. degrees from the Beijing Institute of Technology, Beijing, China, in 2008 and 2010, respectively, and the $\mathrm{Ph} . \mathrm{D}$. degree from the University of Chinese Academy of Sciences, Beijing, China, in 2016, all in electrical engineering.

$\mathrm{He}$ is currently a Research Assistant in the Institute of Electrical Engineering, Chinese Academy of Sciences, Beijing, China. His research interests include electromagnetic interference and electro- 